\title{
Homojen Kum Zeminlerde Optimum İyileştirme Derinliğinin Deneysel Olarak Belirlenmesi
}

\author{
Hüseyin Suha AKSOY ${ }^{1 *}$, Abdullah İÇEN ${ }^{2}$

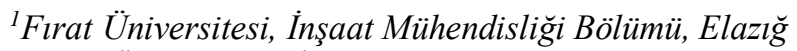 \\ ${ }^{2}$ MunzurÜniversitesi, İnşaat Mühendisliği Bölümü, Tunceli \\ (ORCID: 0000-0003-0564-457X) (ORCID: 0000-0002-7721-1186)
}

\begin{abstract}
$\ddot{O ̈ z}$
$\mathrm{Bu}$ çalışmada, taşıma gücü yetersiz zemin üzerine inşa edilecek bir temelin altında yapılacak iyileştirilmenin derinliği deneysel olarak araştırılmıştır. Bir yapının inşa edileceği zeminin özellikleri, o yapıdan gelecek yükleri karşılamaya yeterli değilse bu durumda zemin iyileştirmesi yapılmaktadır. Zemin iyileştirme yöntemlerinden biri olan jet grout yöntemi ülkemizde de sıklıkla uygulanmaktadır. Zemin iyileştirilmesi yapılırken alttaki sağlam zemin tabakasına kadar iyileştirme yapılmalıdır. Ancak sağlam zemin tabakasının derinde olduğu durumlarda iyileştirmenin hangi derinliğe kadar yapılacağı sadece elastisite teorisinden hesaplanmış kabullere dayanmaktadır. Zemini elastik ve sıkışmaz olarak kabul eden bu teorilere göre temel altı zeminlerde gerilmeler, temelin genişliğinin (B) 1,5-2,0 katı kadar derinliklere kadar etkili olmaktadır. Zemin iyileştirmesi yüksek maliyetli bir işlem olduğundan iyileştirme derinliğinin doğru bir şekilde tespit edilmesi büyük önem taşımaktadır. Yapılan çalışmada, farklı derinliklerde iyileştirilmiş zemine oturan temellerin taşıma gücü deneylerle belirlenmiştir. Taşıma gücü açısından yetersiz zeminleri ve temeli modellemek amacıyla gevşek ve orta sıkılıktaki kumlu zemine oturan çelikten imal edilmiş bir sürekli model temel kullanılmıştır. Sürekli temelin altındaki iyileştirilmiş zemin ise beton bloklar kullanılarak modellenmiş ve deneysel sonuçlar elde edilmiştir. Yapılan deneyler sonucunda, taşıma gücü yetersiz, gevşek zeminlerde yapılacak yüzeysel iyileştirmenin taşıma gücü üzerinde büyük bir etkisinin olmadığı belirlenmiştir. Ancak iyileştirme derinliği arttıkça taşıma gücündeki artışlar büyük oranlarda olmaktadır. Sıkı zeminlerde ise, yapılacak yüzeysel bir iyileştirmenin bile oldukça iyi taşıma gücü değerlerine ulaşılmasını sağladığı anlaşılmaktadır.
\end{abstract}

Anahtar kelimeler: Zemin İyileştirme, İyileştirme Derinliği, Model Deneyler, Taşıma Gücü, Rölatif Sıkılık.

\section{Experimental Determination of Optimal Improvement Depth in Homogeneous Sand Soils}

\begin{abstract}
In this study, the depth of the improvement which will be made under a foundation which lies on soft soil is investigated experimentally. If the characteristics of the soil on which a building will be constructed are not sufficient to bear the loads coming from that building, then the ground is improved. Jet grout It is one of the soil improvement methods and is frequently applied in our country. When stabilizing the soil, improvement should generally be made to the underlying stiff soil layer. However, in cases where the solid ground layer is deep, the depth to which the improvement is to be made depends solely on the assumptions made for the solids calculated from the elasticity theory. According to these theories, which consider the ground as elastic and incompressible, the stresses on the subsoil soils are effective up to a depth of 1,5-2,0 times the width (B) of the foundation. Since soil improvement is a costly process, engineers do not make improvements to these depths. In this study, the bearing capacity of the foundations which are improved at different depths was determined experimentally. In order to model the soft soils and foundations in terms of bearing capacity, a continuous steel model foundation resting on loose and medium-firm sandy ground was used. The improved soil under the continuous foundation was modeled by using concrete blocks and experimental results were obtained. It was determined that the superficial improvement to be made on loose soils with insufficient bearing capacity had no significant effect on bearing capacity. However, as the depth of improvement increases, the increase in bearing capacity increases to a
\end{abstract}

*Sorumlu yazar: saksoy@firat.edu.tr

Geliş Tarihi: 16.07.2019, Kabul Tarihi: 05.12.2019 
great extent. It is understood that even a superficial improvement to be made on hard soils provides very good bearing capacity values.

Keywords: Soil Improvement, Improvement Depth, Model Experiments, Bearing Capacity, Relative density.

\section{Giriş}

Temeller yapı yüklerini zemine aktaran elemanlardır [1]. Yapılacak olan temel, üst yapı yüklerinden gelen gerilmeleri karşılayabilmelidir. Temelin şekline ve boyutlarına üst yapı yüklerine ve zeminin cinsine göre karar verilmektedir. Genel olarak temeller yüzeysel ve derin temeller olarak iki ana başlıkta incelenmektedir. Yüzeysel temeller sürekli, tekil, şerit, radye olarak derin temeller ise kazık, kutu ve keson temel olarak ayrılmaktadırlar. Ancak günümüzde ekonomi ve güvenlik gibi sebeplerle, yüzeysel temel olarak şerit ve radye temeller, derin temel olarak da kazık temeller kullanılmaktadır.

Yapı tasarlanırken kullanılacak temel tipi için yapının ağılığı, yer altı suyunun konumu, zeminin özellikleri, ana kayanın derinliği vb. faktörler göz önüne alınmaktadır. Ekonomik nedenlerden ötürü yüzeysel temeller ilk seçenek olarak değerlendirilmektedir. Eğer zemin, gelecek olan yap1 yüklerini taşımaya elverişli değilse derin temel yapılması seçeneği değerlendirilmektedir. Derin temellerin daha az tercih edilmesinin en büyük nedeni yüksek maliyet ve iş gücü gerektirmesidir.

Bir temelin taşıma gücü, bulunduğu zeminin özelliklerine büyük ölçüde bağlıdır. Bunun yanında gömme derinliği, binadan etkiyen momentler ve yükleme hızı gibi birçok diğer parametre de temelin taşıma gücünü etkilemektedir. Bu nedenle temelin oturduğu zeminin iyi incelenmesi, gerekli önlemlerin alınması ve oluşabilecek olumsuz şartlar göz önünde bulundurulup, önceden önlemler alınarak tasarımın yapılması gereklidir. Toplam oturmaların ve temeldeki farklı oturmaların izin verilen sınırlar içinde kalmasına özen gösterilmelidir. Bir yapı ve temeli çeşitli afetlere karşı ayakta durabiliyorsa, ancak o zaman başarılı bir tasarım ve uygulama yapıldığı düşünülebilir [2].

Temel, üst yapıdan gelen yükleri zemine güvenli bir şekilde aktarmalıdır. Temeli taşıyan zemin bu temelin göçme ihtimaline karşı belirli güvenlikle inşa edilir. Bu güvenlik kriterini tanımlamak için zeminde bir güvenlik sayısı belirlenir. Verilen güvenlik sayısı sayesinde temel, kayma göçmesine ve oturmalara karşı yeterli emniyeti sağlamalıdır.

\subsection{Jet Grout Yöntemi}

Zemin iyileştirme yöntemlerinden biri olan jet grout ülkemizde de hem hılı olması hem de jet grout kolonlarında yüksek dayanım (kum ve çakıl için $>15 \mathrm{MPa}$ ) elde edilmesi [3] nedeniyle sıklıkla kullanılmaktadır. Jet grout diğer adıyla jet enjeksiyonu zemine, yer yer çimento şerbeti enjekte edip taşlaştırarak taşıma gücü yetersiz zeminin mukavemetinin arttırılmasına dayalı bir tekniktir. Bu teknikte zeminin iyileştirilmesi ve üst yapıdan gelen yüklerin daha sağlam bir tabakaya aktarılması amaçlanmaktadır. Genel olarak jet grout, delme ve püskürtme aşaması olmak üzere iki aşamadan oluşmaktadır. Ayrıca jet grout yöntemi enjekte edilen akışkana göre tek, çift ve üç akışkanlı olarak adlandırılmaktadır. Özellikle sağlam zemin tabakasının derinde olduğu durumlarda, kazıklı temeller yerine jet grout yöntemi sıklıkla tercih edilmektedir. Bu iyileştirme işlemi sonucunda zeminin elastisite modülü ve taşıma gücü artarken geçirgenliği azalır. Jet grout kolonu zemine yüksek basınçta enjekte edilen su ve çimento karışımının zemini iterek genişletmesi sonucu oluşturulur. Su-çimento karışımı yüksek hızda zemine enjekte edilerek zemini yırtıp ve genişletir ve soilcrete adı verilen zemin çimento karışımını oluşturur [4].

Jet grout yönteminde özellikle kıyı ve liman yapılarında plug (tıpa) adı verilen bir uygulama yapılır. Bu uygulama için kolonlar çok sıkı şekilde aralarında hiç boşluk olmayacak şekilde imal edilir. $\mathrm{Bu}$ sayede inşa edilecek olan yapının altında yüksek dayanımlı bir blok imal edilmiş olur. Zeminin mukavemeti ciddi derecede artış gösterir ve geçirimsizlik sağlanır (Şekil 1).

Yaptıkları model deneylerde granüler dolgu tabakası serilerek güçlendirilen yumuşak killi zemine oturan sürekli temelin taşıma gücündeki değişimleri teorik olarak gözlemleyen Madhav ve Vitkar; Maksimum taşıma gücü değerinin elde edileceği, en küçük dolgu derinliğinin 2,5B-3,0B (B: Temelin kısa kenarı) arasında olduğunu öne sürmüşlerdir [5].

Das vd. Geogrid donatı ile güçlendirilmiş kum ve doygun killi zeminde şerit temel kullanarak deneyler yapmışlardır. Yapılan deneysel çalışmada optimum toplam donatı derinliği, optimum ilk donatı 
derinliği ve genişliği karşılaştırılmıştır. Kumlarda toplam donatı derinliği $2 \mathrm{~B}$, killerde ise $1,75 \mathrm{~B}$ derinliğe kadar etkili olduğunu gözlemlemişlerdir. Maksimum taşıma gücünün elde edildiği ilk donatı derinliği ise kumlarda $0,30 \mathrm{~B}$, killerde $0,40 \mathrm{~B}$ olarak bulunmuştur [6].
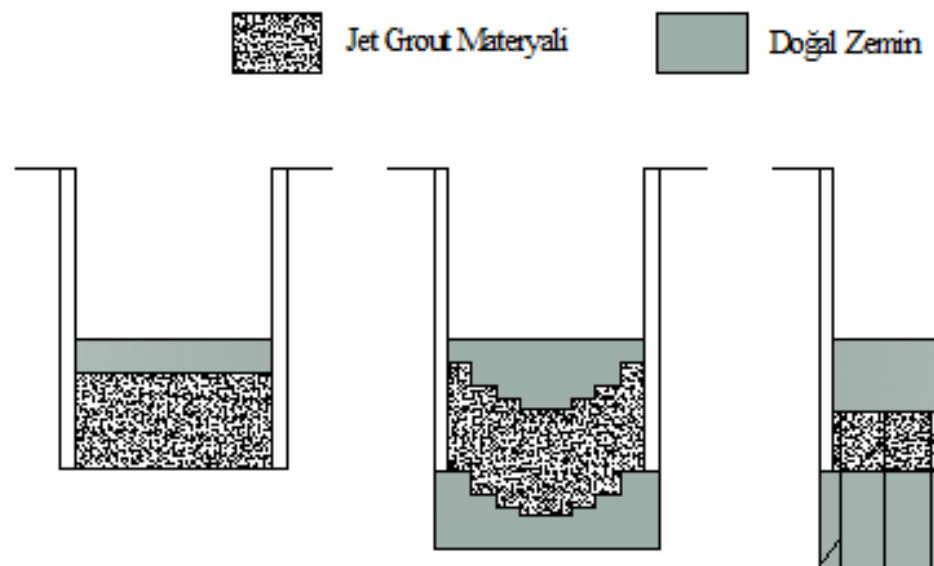

(a)

\section{(b)}

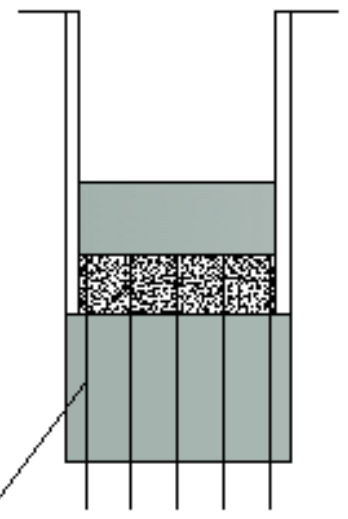

(c)

Şekil 1. Jet grout tıpası örnekleri: (a) ağırlık; (b) ters kemer; (c) ankrajlı [7]

Yetimoglu ve diğerleri, yaptıkları çalışmada, geogridle güçlendirilmiş kumlu zemine oturan bir dikdörtgen temelin performansı laboratuvar ve sonlu elemanlar yöntemi kullanılarak karşılaştırılmıştır. Yapılan araştırmalarda ilk tabakanın derinliği, iyileştirilen tabaka sayısı ve yerleştirilen geogrid uzunluğunun taşıma gücüne etkisi incelenmiştir. $70 \mathrm{~cm} \times 70 \mathrm{~cm}$ boyutlarında $100 \mathrm{~cm}$ derinliğindeki tank $100 \mathrm{kN}$ kapasiteli hidrolik kriko ile yüklenmiştir. 0,076-2 mm aralığındaki kumlu zemin \%70-73 sıkılıkta tanka yerleştirilerek, temel göçene kadar yüklemeye devam edilmiştir. Yapılan deneyler sonucunda ilk tabakanın derinliği, iyileştirilen tabaka sayısı ve yerleştirilen geogridin uzunluğunun temelin taşıma gücüne büyük etkilerinin olduğu gözlemlenmiştir. Tek tabaka olarak serilen geogrid için optimum derinlik $0,3 \mathrm{~B}$, çok tabakalı yerleştirme durumunda yaklaşık olarak $0,25 \mathrm{~B}$ ve geogrid boşluklarının $0,2 \mathrm{~B}$ ile 0,4B arasında olmasının ideal olduğu belirlenmiştir. 1,5B'ye kadar taşıma gücünde artış görülmüştür bu derinlikten sonra, artış azalmıştır. Bu sebeple etkili iyileştirme derinliği 1,5B olarak belirlenmiştir[8].

Kum zemin içine donatı yerleştirip farklı boyutlardaki $(30,46,61,91 \mathrm{~cm})$ kare temellerin donatılı zemindeki taşıma güçlerini inceleyen Adams ve Collin [9]. Parametre olarak donatılar arası mesafe, donatı tabakasını boyu, tabaka sayısı ve zeminin sıkılığ seçmiştir. Bu bulgular sonucunda donatı tabaka sayısı (N) 1 ile 3 arasında seçilmiş olup en yüksek taşıma gücüne 3 tabakalı donatı serilmesi durumunda ulaşılmıştır.

Latha ve Somwanshi, Yaptıkları çalışmada iyileştirilmiş zemine oturan kare bir temelin taşıma gücünü geosentetiklerin çekme dayanımı, sayısı, yerleşme düzeni ve tabaka sayısı gibi faktörleri değiştirerek bu değişimlerin taşıma gücüne etkisini incelemiştir. Deneyler için zemin \%70 sıkılıkta hazırlanmış olup kumlu zemin kullanılmıştır. Deneyler için dayanımı zayıftan güçlüye olacak şekilde 4 farklı geogrid kullanılmıştır. Yapılan deneysel ve nümerik çalışmalar sonucunda efektif iyileştirme derinliğinin temel tabanından itibaren 2B derinlik olduğu belirlenmiştir [10].

Yıldırım ve Yıldız, yaptıkları deneylerde killi bir zeminde geogrid kullanılarak yapılan dolgu ile iyileştirmenin etkisi model deneyleri ile incelemiş̧lerdir. Deney için $60 \mathrm{~cm}$ çapında rijit dairesel çelik model temel kullanılmıştır. Kil zemin üzerine farklı yüksekliklerde yerleştirilen stabilize dolgu ve belli bir H yüksekliğinde stabilize dolgu içerisine yerleştirilen tek sıra ve iki sıra geogridin, kil zeminin taşıma gücüne etkisi ve oturma davranışına etkisi incelenmiştir. Deneylerde $\mathrm{H}$ stabilize yapılacak dolgu derinliği olmak üzere $\mathrm{H}$, temelin çapı (D) ile orantılı olacak şekilde değiştirilmiş ve yüklemeler yapılmıştır. Geogrid donatılı stabilize dolgu tabakası için 2,2x2,2m boyutunda bir alan kullanılmışı̧ı. Deneylerde, dolgu ve donatı nedeniyle oluşan stabilizasyonun yorumlanması sırasında taşıma gücü değeri olarak, temel çapının \%5'ine karşılık gelen oturmanın oluştuğu gerilme değerleri alınmıştır. Stabilize dolgu tabakası $(\mathrm{H}=4 / 6$.D) içerisine, tek tabaka geogridin $u=1 / 6$. D derinliğinde yerleştirilmesi 
durumunda, kil zeminin taşıma kapasitesinde $\% 67$ artış meydana gelmiştir. Stabilize dolgu tabakası ( $\mathrm{H}=4 / 6 . \mathrm{D})$ içerisinde, geogrid donat1 derinlikleri $\mathrm{u}_{1}=1 / 6$. $\mathrm{D}$ ve $\mathrm{u}_{2}=3 / 6$. $\mathrm{D}$ iki tabaka geogrid donatı yerleştirilmesi ile, kil zeminin taşıma kapasitesinde \%74 artış meydana gelmiştir. İki tabaka geogrid donatı kullanılması durumunda, kil zeminin oturması, yaklaşı \% $\% 75$ azalmıştır [11].

Bağriaçık yaptığ zeminlerdeki optimum ilk donatı tabakasının derinliği, deneysel olarak belirlenmiştir. Geogrid donatı, çeşitli derinliklere $(U=2 / 20 \mathrm{~B}, U=3 / 20 \mathrm{~B}, \mathrm{U}=4 / 20 \mathrm{~B}, \mathrm{U}=5 / 20 \mathrm{~B}, \mathrm{U}=6 / 20 \mathrm{~B}, \mathrm{U}=7 / 20 \mathrm{~B}$ ve $\mathrm{U}=8 / 20 \mathrm{~B})$ yerleştirilerek $Z=2$ B derinlikte meydana gelen gerilme değerleri ölçülmüştür. Zemin, $\gamma_{\mathrm{k}}=15,03 \mathrm{kN} / \mathrm{m}^{3}$ olacak şekilde yerleştirilmiştir. Deneyler sonucunda, temel tabanından farklı derinliklere $(U=2 / 20 B$, $\mathrm{U}=3 / 20 \mathrm{~B}, \mathrm{U}=4 / 20 \mathrm{~B}, \mathrm{U}=5 / 20 \mathrm{~B}, \mathrm{U}=6 / 20 \mathrm{~B}, \mathrm{U}=7 / 20 \mathrm{~B}$ ve $\mathrm{U}=8 / 20 \mathrm{~B}$ ) donat tabakası yerleştirilmesi halinde, donatısız duruma göre yaklaşı $\% 10,7, \% 27,2, \% 30,4, \% 38,2, \% 51,7, \% 52,9$ ve $\% 53,6$ oranlarında ek gerilme düşüşleri oluşmuştur. $\mathrm{Bu}$ bulgular sonucunda $\mathrm{U} / \mathrm{B}=6 / 20$ 'ye kadar $\sigma / \mathrm{q}$ oranlarında azalmalar meydana geldiği, $\mathrm{U} / \mathrm{B}=6 / 20$ 'den daha derinde bu azalmaların sabit olduğu görülmüştür. Temel merkezinden itibaren donatı tabakasının derinliği arttıkça, gerilme değerlerinin $(\sigma / q)$, belirli bir donatı tabakası derinliğine kadar azaldığ $1(\mathrm{U} / \mathrm{B}=6 / 20)$, bu derinlikten sonra ise önemli bir azalmanın meydana gelmediği belirlenmiştir. Buna bağlı olarak ise ilk donatı tabakasının optimum derinliği, şerit temel genişliğinin 0,30 katı $(\mathrm{U} / \mathrm{B}=6 / 20)$ olarak belirlenmiştir. Daha önce yapılan çalışmalar 1şığında optimum iyileştirme derinliği kare temel için $0,40 \mathrm{~B}$ dairesel temel için $0,35 \mathrm{D}$ ve sürekli temel için $0,30 \mathrm{~B}$ olarak belirlenmiştir [12]. Bunların yanı sıra birçok araştırmacı geogridle güçlendirilmiş kare temel altındaki zemin üstünde çeşitli parametreleri değiştirerek model deneyler yapmışlardır [13-17].

Daha önce yapılmış çalışmalar incelendiğinde genellikle kare temeller üzerine model deneylerin yapıldığı, özellikle şerit temeller ile ilgili çalışmaların fazla sayıda olmadığı görülmüştür. Ayrıca yapılan iyileştirme araştırmalarının neredeyse hepsinde zemin, geogrid, geotekstil gibi donatılarla iyileştirilmiştir. Jetgrout ile yapılan iyileştirmelerin laboratuvarda modellenmesini amaçlayan araştırmalar literatürde yok denecek kadar azdır.

\section{Materyal ve Metot}

Yapılan deneylerde, Elazı̆̆ ili Murat Nehri yatağında kurulan kum ocağından temin edilen kum kullanılmıştır. Deneyde kullanılan kumun granülometrisi Şekil 2'de görülmektedir.

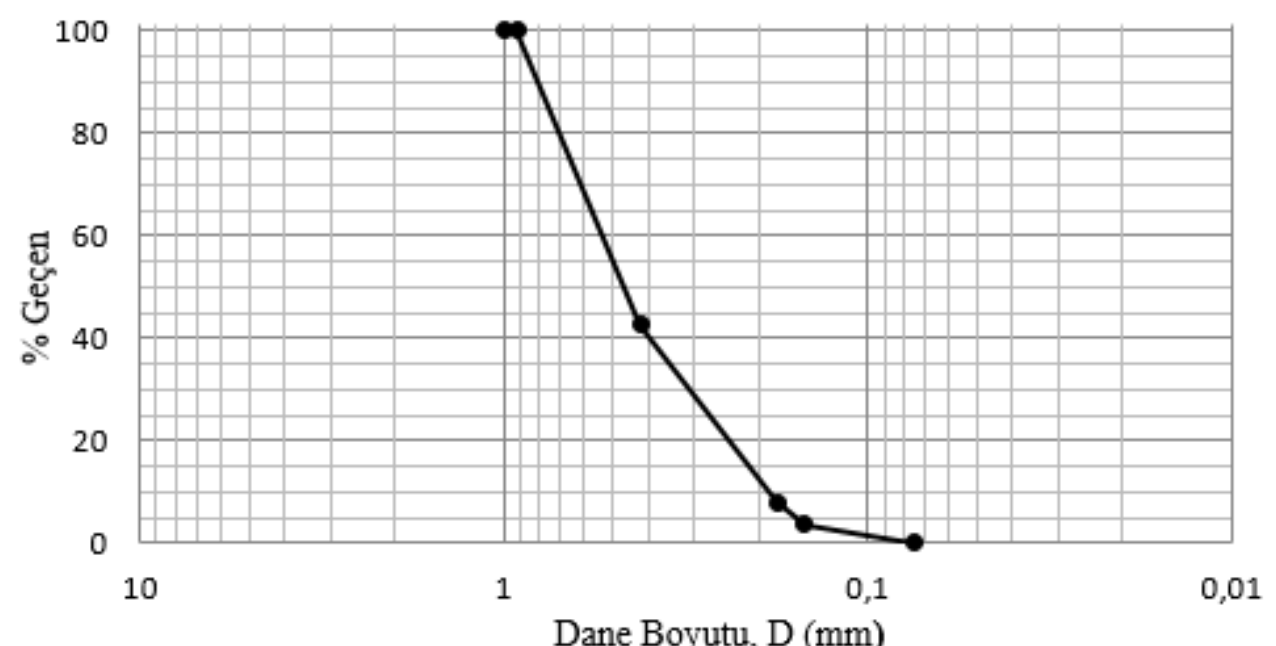

Şekil 2. Yapılmış deneylerde kullanılan kum zeminin dane dağılım grafiği

Zemin iyileştirmesi için yapılan deneylerde kullanılan zeminin parametrelerini belirlemek için, rölatif sıkılık ASTM C128-15 [18], özgül ağırlık ASTM D854-14 [19] ve elek analizi ASTM D422-02 [20] standartlarına uygun şekilde yapılan deneyler sonucunda bu zeminin endeks özellikleri elde edilmiş̧ir ve Tablo 1'de gösterilmiştir. Yukarıda verilen rölatif sıkılıkta hazırlanmış kum numuneler üzerinde ASTM D3080 / D3080M-11 [21] standardına uygun olarak kesme kutusu deneyleri yapılmıştır. Kesme kutusu deneyleri sonucunda her bir sıkılıktaki numuneler için içsel sürtünme açısı $(\phi)$ değerleri belirlenmiştir. Yapılan sıkıştırma deneylerinin sonuçları Tablo 2'de görülmektedir. 
Tablo 1 Deneylerde kullanılan kum zeminin endeks özellikleri

\begin{tabular}{|c|c|}
\hline 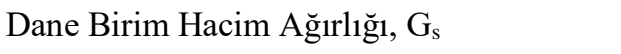 & 2,77 \\
\hline $\mathrm{D}_{10}(\mathrm{~mm})$ & 0.18 \\
\hline $\mathrm{D}_{50}(\mathrm{~mm})$ & 0,45 \\
\hline $\begin{array}{l}\text { Maksimum - Minimum Dane Boyutu, } \\
D_{\max }-D_{\min }(\mathrm{mm})\end{array}$ & $1-0,074$ \\
\hline Maksimum Kuru Birim Hac. Ağ. $\left(\mathrm{kN} / \mathrm{m}^{3}\right)$ & 17,5 \\
\hline Minimum Kuru Birim Hac. Ağ. $\left(\mathrm{kN} / \mathrm{m}^{3}\right)$ & 14,3 \\
\hline Minimum Boşluk Oranı, $\mathrm{e}_{\min }$ & 0,553 \\
\hline Maksimum Boşluk Oranı, $\mathrm{e}_{\max }$ & 0,903 \\
\hline Su Muhtevası (Laboratuvar ortamında) (\%) & 1,02 \\
\hline
\end{tabular}

Tablo 2. Kum malzemesinin relatif sıkılık ve sıkıştırma yöntemi arasındaki ilişkileri

\begin{tabular}{|c|c|c|c|c|}
\hline Sıkıştırma Yöntemi & $\begin{array}{l}\text { Ortalama Kuru } \\
\text { Birim Hac. A } \breve{g} \\
\left(\gamma_{\text {kort }}\right),\left(\mathrm{kN} / \mathrm{m}^{3}\right)\end{array}$ & $\begin{array}{l}\text { Boşluk } \\
\text { Oranı } \\
\text { (e) }\end{array}$ & $\begin{array}{l}\text { Rölatif } \\
\text { S1kılık } \\
\left(\mathrm{D}_{\mathrm{r}}, \%\right)\end{array}$ & $\begin{array}{l}\text { İçsel } \\
\text { Sürtünme } \\
\text { Açıs1 } \\
(\phi)\end{array}$ \\
\hline $10 \mathrm{~cm}$ yükseklikten kuru yağmurlama & 14,83 & 0,868 & 10 & 36 \\
\hline $20 \mathrm{~cm}$ yükseklikten kuru yağmurlama & 15,11 & 0,833 & 20 & 41 \\
\hline $\begin{array}{l}30 \mathrm{~cm} \text { den yağmurlama sonrasında el } \\
\text { kompaktörü ile } 1 \mathrm{sn} \text { vibrasyon } \\
\text { uygulanması }\end{array}$ & 15,71 & 0,763 & 40 & 48 \\
\hline
\end{tabular}

Deneyler için gerekli olan temel boyutları sınır etkisini minimuma indirecek şekilde seçilmiştir. Önceden yapılan hesaplamalar ve deneme deneyleri sonucunda $75 \times 75 \times 100 \mathrm{~cm}$ boyutlarındaki tank için kullanılması uygun olan temel boyutları $6 \times 30 \mathrm{~cm}(\mathrm{~L}=5 \mathrm{~B})$ olarak seçilmiş [22], bu durumda tankın çeperlerinde meydana getirdiği gerilmenin minimum olduğu yapılan teorik hesaplarla görülmüştür. Deney sisteminin şematik gösterimi Şekil 3'de verilmiştir.

Yükleme tankı yağmurlama yapılarak kum zemin ile doldurulmuştur (Şekil 4a. ve 4b.). Daha sonra zeminin yüzeyi düzeltilerek (Şekil4c.) önce iyileştirilmiş zemini temsil eden beton blok ve ardından $6 \mathrm{~cm}$ genişliğinde $30 \mathrm{~cm}$ uzunluğundaki sürekli temel, kum zeminin yüzeyine yerleştirilmiştir (Şekil 5a ve b). Temel, zemine paralel şekilde oturtulduktan sonra iki ucuna oturmaları ölçmek için deplasman ölçerler (LVDT) yerleştirilmiştir. Hidrolik yükleme ünitesi yardımıyla yüklemeler yapılmıştır. Yükler ve deformasyonlar bilgisayara Testbox 1001 marka data logger yardımıyla kaydedilerek alınan veriler incelenmiş ve grafikler yardımıyla temellerin taşıma gücü bulunmuştur.

Zeminin iyileştirilmiş durumunun temsili için temelin altında rijit bir tabaka oluşturulmaya çalışılmıştır. Kullanılan zemine çimento eklenerek $10 \mathrm{MPa}$ dayanımında elde edilen $6 \mathrm{~cm}$ genişliğinde $30 \mathrm{~cm}$ uzunluğunda ve $2 \mathrm{~cm}, 4 \mathrm{~cm}, 8 \mathrm{~cm}$ yüksekliğinde beton bloklar dökülerek zeminin altına konulmuştur. İyileştirilmemiş zeminler üzerinde yapılan deneylerden sonra temelin altına bu beton bloklar yerleştirilerek elde edilen oturma-yük grafiğinden taşıma güçleri belirlenmiştir. Tankın içerisindeki zemin belirli bir yüksekliğe kadar doldurulmuş, daha sonra 2, 4 ve $8 \mathrm{~cm}$ yüksekliğindeki beton bloklar temelin altına gelecek şekilde yerleştirilerek yüklemeler tamamlanmıştır. Şekil 4 a.'da zeminin içine yerleştirilen çelik model temel ve beton blok görülmektedir. 


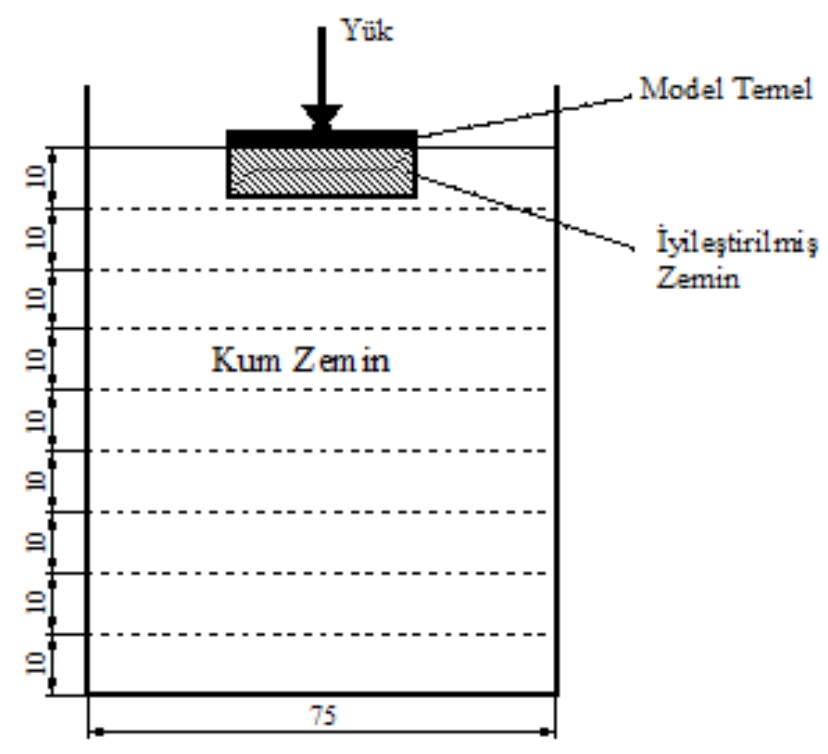

Şekil 3. Deney düzeneğinin şematik gösterimi

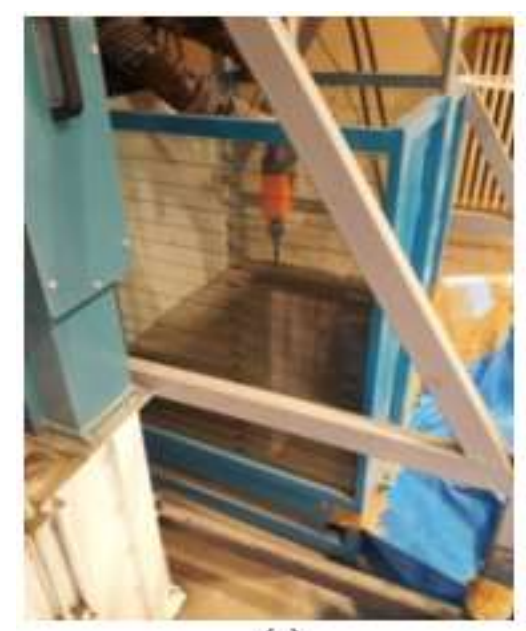

(a)

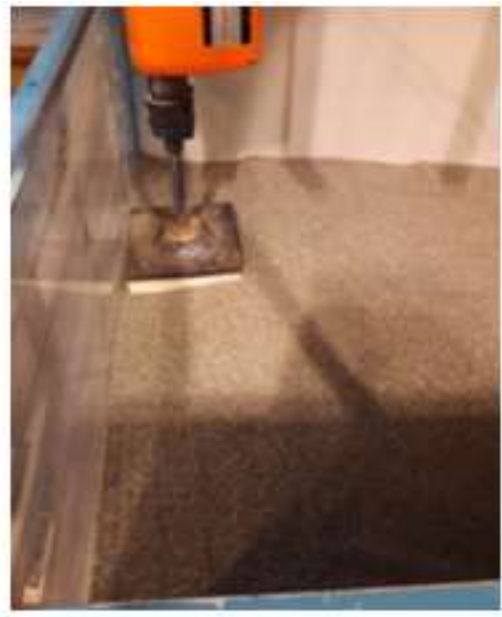

(b)

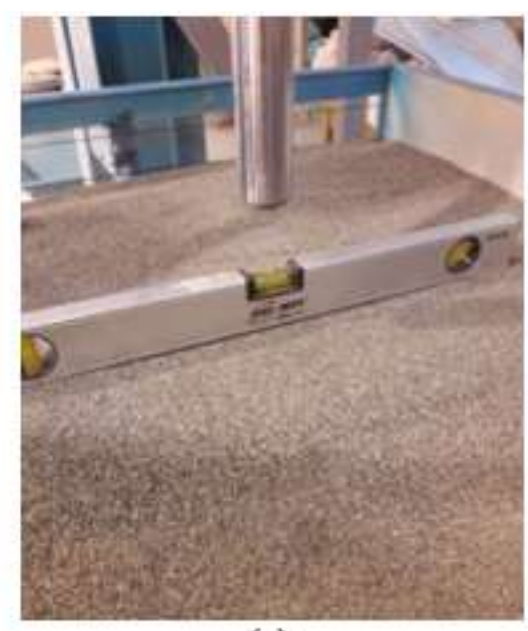

(c)

Şekil 4. (a-b) Deney takında istenilen sıkılı̆̆ın elde edilmesi için kompaktör uygulanması c) Su terazisi kullanılarak temelin oturacağı yüzeyin kontrol edilmesi

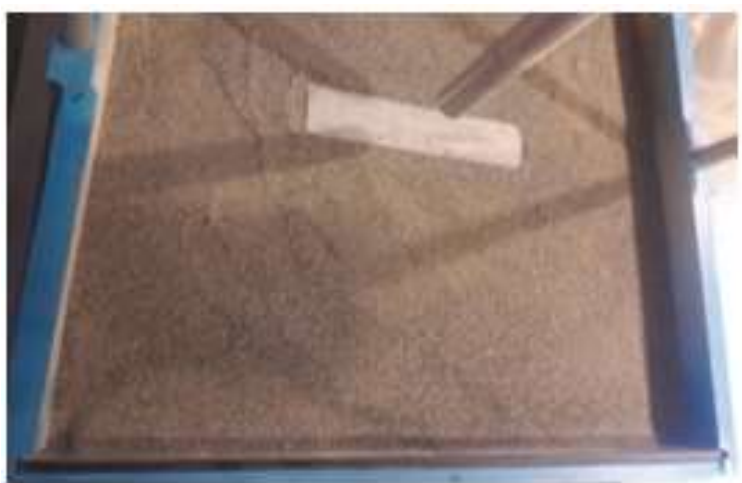

(a)

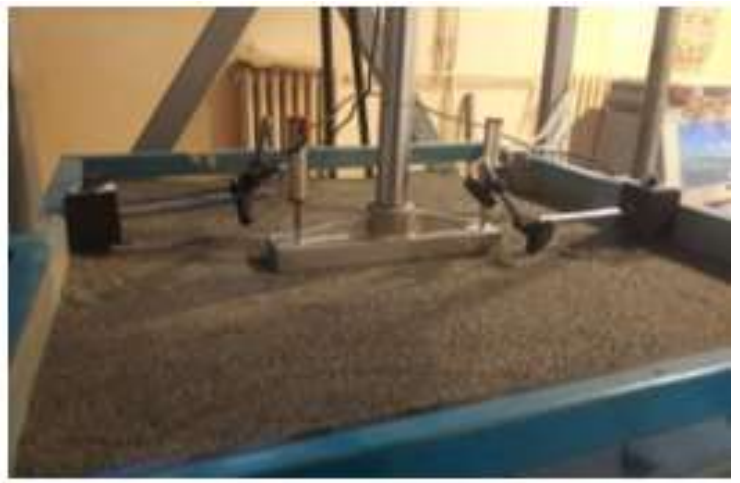

(b)

Şekil 5. a) Zemin yüzeyi düzleştirildikten sonra yerleştirilen beton blok b) Şerit temel 


\section{Bulgular ve Tartışma}

$\mathrm{Bu}$ çalışmada yapılan model deneylerinin sonuçları incelendiğinde iyileştirme yapılması taşıma gücünü tüm deneylerde arttırmıştır. Fakat yapılan iyileştirme sonucunda elde edilen taşıma gücünün iyileştirilme yapılmamış duruma oranı olarak tanımlanan taşıma kapasitesi oranının (TKO) doğrusal olarak artmadığı gözlemlenmiştir. Taşıma kapasitelerinin ve TKO'larının değişimleri Tablo 3'de görülmektedir.

Tablo 3. Taşıma güçleri ve taşıma kapasitesi oranlarının sıkılıkla değişimi

\begin{tabular}{ccccccc}
\hline & \multicolumn{2}{c}{$\%$ \%10 Sıkılık } & \multicolumn{2}{c}{$\%$ \% S1k Sıkılık } \\
\hline $\begin{array}{c}\text { İyileştirme } \\
\text { Derinliği }\end{array}$ & Taşıma Gücü (kN) & TKO & Taşıma Gücü $(\mathrm{kN})$ & TKO & Taşıma Gücü (kN) & TKO \\
\hline 0 & 0,47 & & 1,29 & & 5,90 & \\
B/3 & 0,50 & 1,06 & 1,57 & 1,22 & 8,7 & 1,47 \\
$2 \mathrm{~B} / 3$ & 0,85 & 1,81 & 1,97 & 1,53 & 9,20 & 1,56 \\
$4 \mathrm{~B} / 3$ & 1,60 & 3,40 & 2,55 & 1,98 & 12,17 & 2,06 \\
\hline
\end{tabular}

$\mathrm{Dr}=\% 10$ olan zeminde $\mathrm{B} / 3$ derinliğinde yapılan iyileştirmenin çok bir etkisinin olmadığ $(\% 6$ artış) görülmektedir. Ancak iyileştirme derinliği arttıkça TKO'nın geometrik olarak arttığ ve 4B/3 iyileştirme derinliğinde $\% 240$ artışa neden olduğu belirlenmiştir. $\mathrm{Dr}=\% 20$ olan zeminde $\mathrm{B} / 3$ derinliğinde yapılan iyileştirmenin taşıma gücünde $\% 22$ artışa sebep olurken $4 \mathrm{~B} / 3$ iyileştirme derinliğinde $\% 98$ artışa neden olduğu belirlenmiştir. Dr $=\% 40$ olan zeminde ise $\mathrm{B} / 3$ derinliğinde yapılan iyileştirmenin taşıma gücünde $\% 47$ artışa sebep olurken $4 \mathrm{~B} / 3$ iyileştirme derinliğinde $\% 106$ artışa neden olduğu belirlenmiştir.

Yukarda belirtildiği gibi gevşek zeminlerde yüzeysel iyileştirmenin taşıma kapasitesine büyük bir katkısı olmamaktadır. Daha sıkı zeminlerde ise yapılacak yüzeysel bir iyileştirmenin bile oldukça iyi taşıma gücü değerlerine ulaşılmasını sağladığı anlaşılmaktadır. Ancak bu zeminlerde iyileştirme derinliğinin artması TKO'nında büyük artışlara sebep olmamaktadır. $\mathrm{Dr}=\% 40$ zeminde yüzeysel (B/3) iyileştirme \%47 artışa neden olurken iyileştirme derinliğinin 4 kat artması taşıma gücünü ancak 2 kat artmasına sebep olmuştur. Oysaki gevşek zeminde $(\mathrm{Dr}=\% 10)$ bu artış 3.4 kat olmuştur. Taşıma güçlerindeki değişimler Şekil 6. de görülmektedir.

B/3 derinlikte $(2 \mathrm{~cm})$ iyileştirme yapılması durumunda, TKO'nın sıkılıkla arttığı gözlemlenmiştir. Bununla birlikte iyileştirilen tabakanın derinliği arttırıldıkça taşıma kapasitesi oranında büyük bir artışın olmadığ 1 görülmektedir, $2 \mathrm{~B} / 3(4 \mathrm{~cm})$ ve $4 \mathrm{~B} / 3(8 \mathrm{~cm})$ derinliklerde yapılan iyileştirmenin en etkili olduğu sıkılık \%10'dur. Şekil 7.'daki grafik incelendiğinde, genel olarak her sıkılık için iyileştirme derinliği arttıkça taşıma kapasitesi artmıştır.

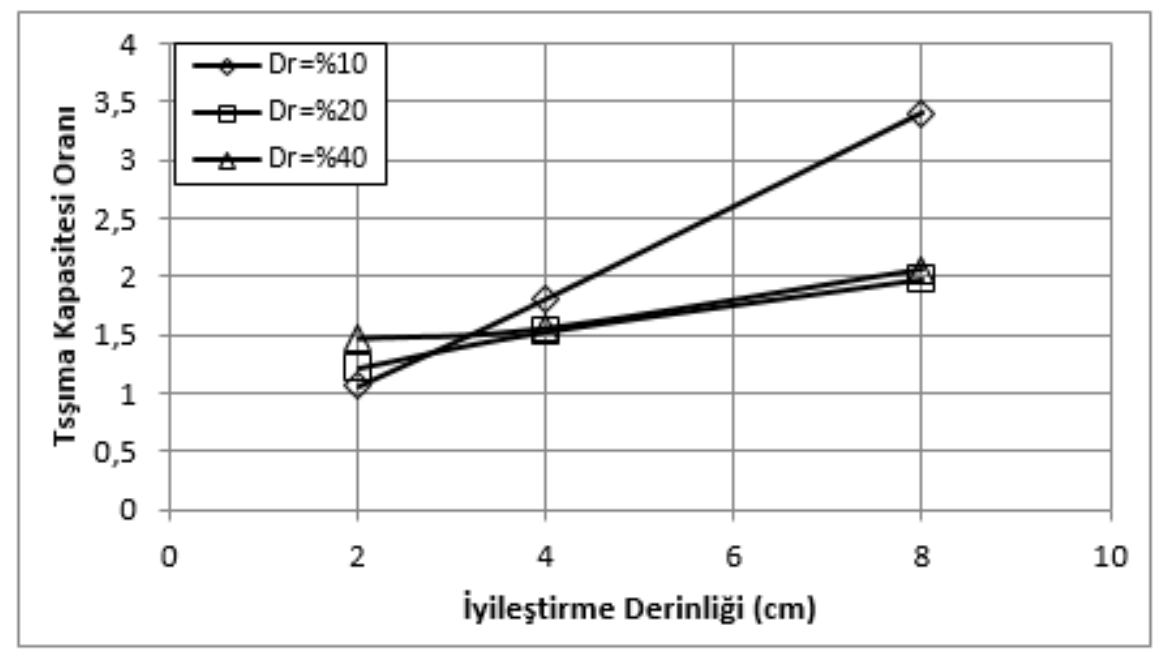

Şekil 6. Taşıma kapasitesi oranının iyileştirme derinliği ile değişimi 


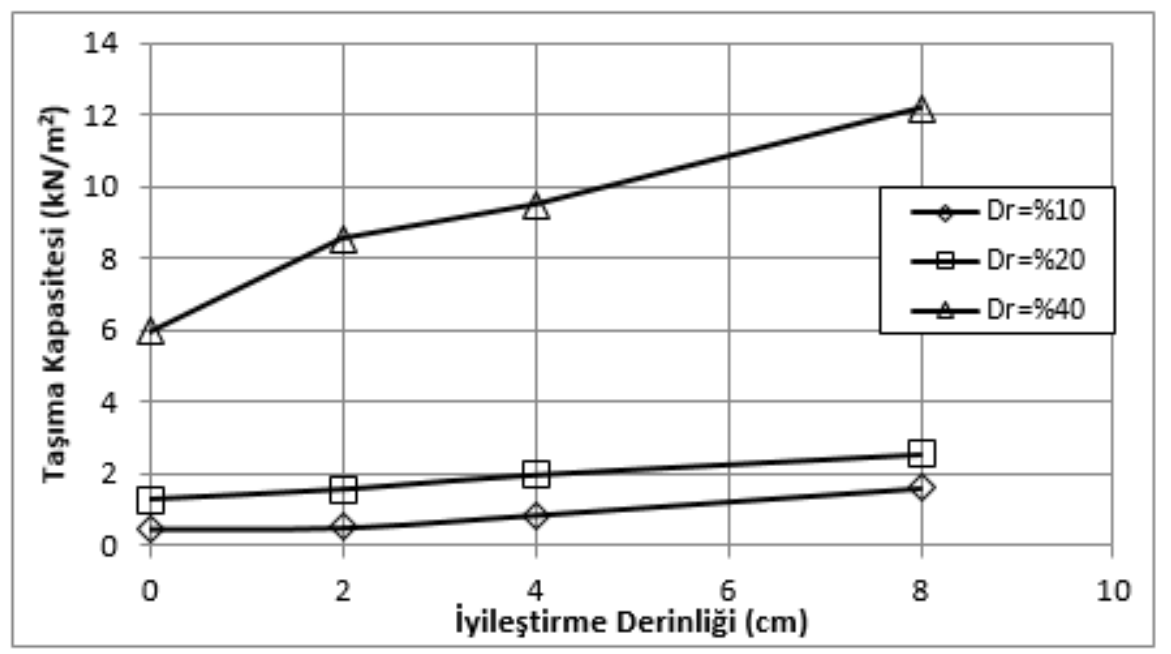

Şekil 7. Taşıma kapasitesinin iyileştirme derinliği ile değişimi

\section{Sonuç ve Öneriler}

$\mathrm{Bu}$ çalışmada, taşıma gücü yetersiz zemin üzerine inşa edilecek bir temelin altında yapılacak iyileştirilmenin derinliği, laboratuvarda model deneyleri yapılarak araştırılmıştır. Deney sonuçlarından da görüleceği (Şekil 6 ve 7) gibi taşıma gücü yetersiz, gevşek zeminlerde yapılacak yüzeysel iyileştirmenin taşıma gücü üzerinde büyük bir etkisinin olmayacağı anlaşılmaktadır. Ancak iyileştirme derinliği arttıkça taşıma gücündeki artışlar büyük oranlarda olmaktadır. Sıkı zeminlerde ise yapılacak yüzeysel bir iyileştirmenin bile oldukça iyi taşıma gücü değerlerine ulaşılmasını sağladığı anlaşılmaktadır. Ancak bu zeminlerde iyileştirme derinliğinin artması taşıma kapasitesi oranında büyük artışlara sebep olmamaktadır. Yine sıkı zeminlerde iyileştirme derinliği arttıkça taşıma gücü artmakta ancak artış oranları daha sınırlı olmaktadır. Çok gevşek zeminlerde, yetersiz iyileştirmenin taşıma gücünde önemli bir artışa neden olmadığı belirlenmiştir. Sık1 zeminlerde inceleme derinliğinin 4 kat artması taşıma gücünü 2 kat artırırken, gevşek zeminlerde inceleme derinliğinin 4 kat artması taşıma gücünü 3,4 kat artmasına neden olmuştur. Bu nedenle zemin iyileştirmesinin taşıma gücü yetersiz zeminlerde daha makul bir çözüm olduğu anlaşılmaktadır.

\section{Yazarların Katkısı}

Çalışmaya her iki yazar da eşit oranda katkı sunmuştur.

\section{Çıkar Çatışması Beyanı}

Yazarlar arasında herhangi bir çıkar çatışması bulunmamaktadır.

\section{Araştırma ve Yayın Etiği Beyanı}

Yapılan çalışmada araştırma ve yayın etiğine uyulmuştur.

\section{Kaynaklar}

[1] Uzuner B.A. 2007. Temel Zemin Mekaniği. Derya Kitabevi, 485s, Trabzon.

[2] Çinicioğlu S.F. 2005. Zeminlerde statik ve dinamik yükler altında taşıma gücü anlayışı ve hesabı. İMO Seminer, 19-20 Şubat, İstanbul, pp.1-25.

[3] Baumann V. 1984. Das soilcrete-verfahren in der baupraxis. Vortrage der Baugrundtagung, 1315 September, Dusseldorf, pp.49-83.

[4] Toğrol E. 1998. Jet-Grout Kolonların Yapımında Kalite Denetimi. 7. Ulusal Zemin Mekaniği ve Temel Mühendisliği Kongresi, 22-23 Ekim, İstanbul, pp. 393-402. 
[5] Madhav M.R., Vitkar P.P. 1978. Strip Footing on Weak Clay Stabilizated with a Granuler Trench or Pile. Canadian Geotechnical Journal, 15 (4): 605-609.

[6] Das B.M., Shin E.C., Omar M.T. 1994. The Bearing Capacity of Surface Strip Foundations on Geogrid Reinforced Sand and Clay. Geotech. and Geological Eng., 12 (1): 1-14.

[7] Modoni G., Flora A., Lirer S., Ochmański M., Croce P. 2016. Design of jet grouted excavation bottom plugs. Journal of Geotech. and Geoenvir. Engineering, 142 (7): 04016018.

[8] Yetimoglu T., Wu J.T., Saglamer A. 1994. Bearing capacity of rectangular footings on geogridreinforced sand. Journal of Geotechnical Engineering, 120 (12): 2083-2099.

[9] Adams M.T., Collin J.G. 1997. Large Model Spread Footing Load Tests on Geosynthetic Reinforced Soil Foundation. Journal of Geotechnical and Geoenvironmental Eng., 123 (1): 6672.

[10] Latha G.M., Somwanshi A. 2009. Bearing capacity of square footings on geosynthetic reinforced sand. Geotextiles and Geomembranes, 27 (4): 281-294.

[11] Yıldırım D., Yıldız A. 2010. Geogrid Donatılı Stabilize Dolgu Tabakası İle Kil Zeminlerin İyileştirilmesi. Çukurova Üniversitesi Fen Bilimleri Dergisi, 22 (2): 29-38.

[12] Bağrıaçık B. 2016. Donatı Tabakasının Optimum Derinliğinin Farklı Temel Şekilleri için Değerlendirilmesi. Çukurova Üniversitesi Mühendislik-Mimarlık Fakültesi Dergisi, 31 (2): 187194.

[13] Akinmusura J.O., Akinbolade J.A. 1981, Stability of Loaded Footings on Reinforced Soil. ASCE Journal of Geotechnical Engineering Division 107 (6): 819-827.

[14] Saglamer A., Duzceer R., Gokalp A., Yilmaz E. 2001. Recent applications of jet grouting for soil improvement in Turkey. Proceedings of the International Conference on Soil Mechanics And Geotechnical Engineering, 27-31 August, Istanbul, pp. 1839-1842.

[15] Patra C.R., Mandal J.N., Das M.B. 2005. Ultimate Bearing Capacity of Shallow Foundation on Geogrid-Reinforced Sand. Proceedings of the 16th International Conference on Soil Mechanics and Geotech. Eng., 12-15 September, Osaka, Japan, pp.12-16.

[16] Deb K., Dey A., Chandra S. 2007. Modeling of Layered Soil System. 1st Indian Young Geotechnical Engineers Conference, 11-23 September, Hyderabad, India, pp. 50-55.

[17] Kumar A., Ohri L.M., Bansal K.R. 2007, Bearing Capacity Tests of Strip Footings on Reinforced Layered Soils. Geotechnical and Geological Engineering, 25 (2): 139-150.

[18] ASTM C128-15. 2015. Standard Test Method for Relative Density (Specific Gravity) and Absorption of Fine Aggregate. American Society of Testing and Materials ASTM.

[19] ASTM D854-14. 2014. Standard Test Methods for Specific Gravity of Soil Solids by Water Pycnometer. American Society of Testing and Materials ASTM.

[20] ASTM D422-02. 2006. Standard Test Method for Particle Size-Analysis of Soils. American Society of Testing and Materials ASTM.

[21] ASTM D3080/D3080M-11. 2011. Standard test method for direct shear test of soils under consolidated drained conditions. American Society of Testing and Materials ASTM.

[22] Önalp A., Sert S. 2016. Geoteknik Bilgisi III - Bina Temelleri. Birsen Yayınevi, 375s. İstanbul. 